\title{
Navigating the Gluten-Free Boom: The Dark Side of Gluten Free Diet
}

\author{
Aaron Lerner ${ }^{1 *}$, Thomas O'Bryan ${ }^{2}$ and Torsten Matthias ${ }^{1}$ \\ ${ }^{1}$ Aesku.KIPP Institute, Wendelsheim, Germany, ${ }^{2}$ Gastroenterology, Clinical Practice and Institute of Functional Medicine, The \\ National University of Health Sciences, San Diego, CA, United States
}

In gluten dependent conditions the gluten free diet is the cornerstone of therapy, decreasing disease activity, improving health and quality of life and treating or preventing the associated complications. Gluten withdrawal implies strict and lifelong elimination not only of wheat, barley, rye, and wheat-contaminated oats, but also of numerous non-nutritional products where components of wheat are often added. Due to multiple reasons the diet is difficult to follow and the long-term adherence is decreased with time. The present review summarizes the dark side of gluten restriction where nutritional deficiencies, toxicity, morbidity, mortality, and mental health problems are reported. The aim being to increase awareness, avoid, detect and treat the side effects and to promote a healthier nutrition, for the patient's benefits.

OPEN ACCESS

Edited by:

Steven Thomas Leach, University of New South Wales, Australia

Reviewed by:

Govind K. Makharia, All India Institute of Medical

Sciences, India

Gabriel Samasca, Iuliu Haţieganu University of Medicine and Pharmacy, Romania

*Correspondence: Aaron Lerner aaronlerner1948@gmail.com

Specialty section: This article was submitted to Pediatric Gastroenterology, Hepatology and Nutrition, a section of the journal Frontiers in Pediatrics

Received: 01 June 2019 Accepted: 26 September 2019 Published: 15 October 2019

Citation:

Lerner A, O'Bryan T and Matthias T (2019) Navigating the Gluten-Free Boom: The Dark Side of Gluten Free Diet. Front. Pediatr. 7:414. doi: 10.3389/fped.2019.00414
Keywords: celiac disease, gluten free diet, gluten withdrawal, side effects, nutritional deficiency, non-celiac wheat sensitivity, morbidity, mortality

\section{INTRODUCTION}

The global population has more than doubled in the last 40 years supported by the "green revolution" in agriculture producing high-yield grain varieties, including semi-dwarf, high-yield, disease resistant varieties of wheat, that are central to the modern diet (1). Awarding the Nobel Peace Prize in 1970 to Norman Ernest Borlaug recognized the value of dwarf wheat to humanity.

Celiac disease has traditionally been clinically considered and then investigated with patients presenting with gastrointestinal (GI) symptoms. However, for every adverse reaction to wheat presenting with GI symptoms, there are 8 presenting without GI symptoms (2). Thus, dependence on GI complaints as a prerequisite in considering an adverse reaction to wheat, will allow a majority to escape diagnosis. This is a critical point of recognition for the Clinician when considering an association of wheat related disorders (WRD) and the potential value of a Gluten-Free Diet (GFD).

The 8:1 ratio of extra-intestinal vs. intestinal symptoms is not limited to celiac disease. In a prospective 1-year study of suspected non-celiac gluten sensitivity (NCGS) related disorders from 38 Italian centers-all recognized as referral centers of excellence and included in the register of the Italian Health Ministry for the diagnosis of gluten-related disorders, 53\% of patients presented with non-abdominal complaints. The most frequent extraintestinal manifestations were fatigue and lack of well-being, reported by 64 and 68\%, respectively, of the enrolled subjects. In addition, a high prevalence of neuropsychiatric symptoms including headache (54\%), anxiety (39\%), "foggy mind" (38\%), and arm/leg numbness (32\%) were recorded. Other extra intestinal manifestations emerging from the analysis of the survey responses were joint/muscle pain often misdiagnosed as fibromyalgia (31\%), weight loss $(25 \%)$, anemia $(22 \%)$-due both to iron deficiency and low folic acid, depression (18\%), dermatitis (18\%), and skin rash (29\%), Umberto et al. (3). With its global impact in the body and lack of isolated tissue vulnerability, a high degree of suspicion is required for a Clinician to investigate a presenting patient for a WRD. 
GFD, the mainstay of treatment for celiac disease (CD), is increasingly being adopted by people without a diagnosis of celiac disease. Gluten-free (GF) eating patterns have become a mainstream phenomenon during recent years, and nearly onethird of Americans report having attempted to eliminate or reduce the amount of dietary gluten they consume (4).

Currently, wheat is the most widely cultivated crop in the world and the dominant staple crop in temperate countries, providing between 20 and $50 \%$ of the total calories intake. The gluten family of proteins are the major proteins of wheat and are very important for wheat survival. In industrial countries, wheat makes substantial contribution to diet and health, particularly providing dietary fibers, B vitamins (B1, B2, B3, B6, B9) and mineral micronutrients, notably iron, zinc, and selenium. Hence, restricting wheat intake, without the guided support of a welltrained Registered Dietician, Nutritionist, or Physician can have serious consequences for the intake of essential nutrients and other beneficial components. GF menus are significantly lower in protein, magnesium, potassium, vitamin E, folate, and sodium, with suggestive trends toward lower calcium and higher fat (4). Equivalent sources of essential nutrients must be provided.

A common misnomer is that GF substitute foods are healthy. There is no evidence to support such a claim. While it is true that GF foods will eliminate a primary antigenic component of the diet, GF foods are calorie rich and nutrient poor. Restricting the intake of wheat in the diet can have serious consequences for the intake of essential nutrients and other beneficial components unless equivalent sources of these are provided (5). It is generally considered that GF foods are less nutritionally adequate than standard products. GF bread products were significantly higher in fat and fiber. All GF products were lower in protein than standard products. Only 5\% of GF breads were fortified with all four mandatory fortification nutrients (calcium, iron, niacin, and thiamin), only $9 \%$ of GF bread products were fortified with thiamin, riboflavin, and niacin, and $28 \%$ of GF breads were fortified with calcium and iron only. This lack of fortification may increase the risk of micronutrient deficiency in celiac sufferers.

Based on the modern awareness on the nutrition-health bidirectional connections, the topic of healthy food is today's fashionista. According to the World Health Organization, a healthy food should prevent under and over nutrition and protect from chronic, non-communicable diseases (6). Controversially and in real facing of the mirror, the metabolic syndrome, allergy, cancer, stroke and autoimmune conditions are surging in the last decades (7-9). All 5 of these conditions have inflammation as the igniting spark associated with their development. Mirroring those alarming surges with simultaneous substantial declines in infectious diseases set the stage for the hygiene hypothesis. However, new scientific winds are blowing and "cleaning" the hygiene related concepts and prioritize the friendly microbiota over the pathogenic dysbiota in shaping gut homeostasis (10, 11). Changes in the microbiome on a GFD have substantial influence on the pro/dysbiotic environment of the GI Tract. It

Abbreviations: CD, celiac disease; GF, gluten free; GFD, gluten free diet; GI, gastrointestinal; NCGS, non-celiac gluten sensitivity; WRD, wheat related disorders. appears that intimate evolutionarily relationships are important, indispensable and crucial for bugs and us to develop and survive (12-14). We need them and they can't survive without our gut hospitality. Here comes the major environmental factor that keeps the physiological microbiome at bay: healthy, wellbalanced food. Many food intolerances and allergies, metabolic conditions, genetic abnormalities, autoimmune diseases, and other medical conditions require special or controlled diets, GFD being one of them. Due to the incomplete adoption of a GFD outside the boundaries of a proven gluten related disease, the present review will concentrate on the dark side of gluten withdrawal.

\section{Gluten Dependent Conditions}

Several diseases are considered to be gluten dependent. Gluten allergy that follows immune allergic mechanisms, celiac disease (CD), gluten ataxia and dermatitis herpetiformis as autoimmune conditions and the recently describe entity: nonceliac gluten/wheat sensitivity $(15,16)$. Celiac disease is a lifelong autoimmune disease affecting genetically predisposed individuals by the consumption of prolamins like wheat, barley, rye, and contaminated oats (17). It affects averagely $1-1.5 \%$ of Western populations, its incidence is surging worldwide even in fareast and under developed countries, a trend shared by many other autoimmune diseases $(8,18)$. Co-emergence of increased gluten consumption and $\mathrm{CD}$ prevalence and its recent changing epidemiology, reinforce the environmental over genetic influence in the contemporary $\mathrm{CD}$ surge. The only proven therapy is a lifelong GFD that reverse most of the symptoms, improve substantially mucosal pathology, near to the normal histology and prevent some of the long term complications. GFD can improve the other gluten dependent conditions. Prevent the allergy, alleviate the skin eruption in dermatitis herpetiformis, and potentially improve the ataxia in gluten ataxia. Despite being an effective therapy, multiple difficulties arise during its implementation.

\section{Gluten Free Diet}

The only recommended and effective therapy for $\mathrm{CD}$ is strict exclusion of gluten for life. Despite strict adherence, complete mucosal recovery is rarely obtained. In most cases, a variable degree of inflammation persists characterized by persistent intraepithelial lymphocytosis with or without associated glandular hyperplasia (Marsh I-II/Grade A) at control biopsy usually performed after 6-18 months of GFD. Complete normalization to Marsh 0 stage was observed in $8 \%$ of patients, with Marsh I and II lesions persisting in 65\% of patients with duodenal atrophy at baseline (19). And in the largest study ever done on Mortality and Celiac Disease, of 46,121 total biopsies, Marsh I-II was identified in 13,306 specimens. This was associated with a $72 \%$ increased risk of mortality in the first year after diagnosis (20). This is almost double the increased mortality in the first year after diagnosis with total villous atrophy CD (39\%). The persistent duodenal intraepithelial lymphocytosis in CD patients during GFD is not eliminated by a gluten contamination elimination diet and is independent of the time length of GFD (21). GFD include withdrawal of 
wheat, barley, rye, contaminated oats, spelt, kamut, triticale, malt, or their hybridized strains. Natural gluten free nutrients like vegetables, legumes, fruits, fish or unprocessed meat, milk and dairy products, and eggs are allowed. By various industrial nutritional technics, gluten can be eliminated or decreased to $<20 \mathrm{ppm}$, the amount allowed, for the CD patients by the European codex alimentarius (22). At least for now, GFD is fully recommended for CD, gluten allergy, dermatitis herpetiformis, and gluten ataxia. For the newly evolved entity of non-celiac gluten sensitivity, GFD might alleviate their symptoms, though, the pathophysiological pathways, offending environmental factors, strict diagnostic criteria and therapeutic nutrient withdrawal policy, are far from being resolved (23-25). The diagnostic criteria for $\mathrm{CD}$ and its related extra-intestinal manifestations $(26,27)$ are quite clear and the recommended gluten avoidance is obvious, but the lifelong restriction is a bumpy road $(28,29)$. The difficulties in following GFD and the reasons for poor patient's compliance were summarized recently $(28,29)$. Gluten is considered as a universal food additive as a thickener, flavor enhancer, filler, emulsifier, or texture modifier in many processed food products $(6,30)$. The present review will zoom on the deleterious effects of GFD, but, before will describe the nowadays fashionista of gluten/wheat avoidance.

\section{GLUTEN WITHDRAWAL FASHIONISTA}

In parallel to the surge in gluten-related disorders prevalence, the numbers of people that empirically try to avoid gluten, for a variety of signs, reasons, and symptoms are gradually and continuously rising.

It becomes a very popular diet in contemporary history. Although many report improved health, increased energy, social and food industries and several best-selling books fuel its popularity, there is little evidence to explain the above mentioned reports. The opponents to and the approvers of gluten came to the forefront of popular nutritional discussions and "going gluten-free" has become mainstream in Western populations $(31,32)$. Currently, $\sim 25 \%$ of the population reports keeping a GFD, many without adequate knowledge "requesting GF meals and ordering bread pudding for dessert" $(33,34)$. On the other hand adherence to GFD by the gluten dependent patients is poor and deserve continuous nutritional education and behavioral reinforcement programs $(35,36)$. No doubt, gluten restriction became today's fashion trend (37).

Recognizing that dietary changes alter the gut microbiome in humans within 24-48 h (38), a 2011 study demonstrated that for celiac children following a GFD for 2 years, the GFD did not completely restore the microbiota and, consequently, the metabolome of CD children (39). In another study, 10 healthy participants who did not have $\mathrm{CD}$ or a recognized gluten sensitivity, following a GFD, found that their diet alone created a pro-inflammatory GI environment $100 \%$ of the time. Researchers concluded that when individuals discontinue eating wheat, the reduced polysaccharide intake (prebiotics) creates a shift in the diversity of the intestinal microbiome, with lowered bifidobacterium and lactobacillus and concomitant increase in enterobacteriaceae, diminishing short chain fatty and organic acids and thus reducing competence of the immunomodulatory role of the microbiome with lowered $\mathrm{TNF} \alpha$, IFN gamma, IL-8, and IL-10. This outcome creates a pro-inflammatory environment (40).

With wheat providing 78\%, and barley (3\%), together providing $81 \%$ of oligo fructose and inulin for average North Americans (41), a non-guided GFD, which does not purposefully replace these critical fructan prebiotics (such as Arabinoxylose), runs the risk of creating a starvation state for the resident probiotics, easily creating an inflammatory cascade environment in the microbiome. Without these fructan prebiotics in wheat, the microbiota which was accustomed to this family of prebiotics die off, creating a pro-inflammatory environment (42).

An example of the potential complication of the above dynamic is the production of trimethylamine $\mathrm{N}$-oxide. This metabolite of choline increases atherosclerotic plaque size, triggers prothrombotic platelet function, promotes arterial thrombus growth (43), and predicts risk for cardiovascular diseases (44). This is produced by action of genera Allobaculum and Candidatus arthromitus as well as the family Lachnospiraceae, which were identified in the cecal microbiota producing higher levels of serum trimethylamine $\mathrm{N}$ oxide (45). Hence, the composition of the commensal microbiota is an emerging risk factor for cardiovascular diseases.

In view of the rising popularity of gluten restricted products, the present review will summarize the dark side of the GFD, rather than describing the macro and micronutrients deficiencies, extensively described in naïve or untreated $C D$ patients (46).

\section{NUTRITIONAL DEFICIENCIES}

GFD is an unbalanced diet that buries in its lap multiple nutritional deficiencies. It is known that gluten restricted products are of poorer nutritional value, lower quality, unpleasant mouth-feel, less flavored and diminished viscoelasticity of bread products. Table 1 summarizes those deficiencies while being treated with GFD. The fact that most of the GFD products are not fortified, further aggravates the deficiencies. Summarizing surveys on nutritional profiles of gluten free, compared to gluten containing food products, Melini et al. showed that the GFD is deficient in fibers, proteins, folate, iron, potassium, and zinc, while higher in fat, carbohydrate, sugars, FODMAP's, and sodium, in most of the surveys (6).

The substitution of gluten containing prolamins by rice and corn put the patient at risk of protein, fiber and folate deficiencies $(50,60)$ and higher glycemic index (60). Thus, partially explaining the higher rate of metabolic syndrome and cardiovascular morbidity reported in naïve and treated $C D$ patients (61-64). One must remember the association of an activated immune response to other foods in over $50 \%$ of celiacs maintaining an inflammatory environment in the gut (65).

\section{TOXICITY}

There are two main sources for toxic or potentially deleterious compounds, while consuming GFD. The first one is due to the common consumption of fish and rice. Both have increased levels 
TABLE 1 | Nutritional deficiencies, excesses and toxicity in gluten free products.

\begin{tabular}{|c|c|c|}
\hline $\begin{array}{l}\text { Nutrient } \\
\text { abnormality/deficiency }\end{array}$ & Excessed components & Toxicity \\
\hline Iron & Proteins & $\begin{array}{l}\text { Heavy metals: arsenic, } \\
\text { mercury, lead, cadmium }\end{array}$ \\
\hline Calcium, sodium & Fat, saturated fatty acids & $\begin{array}{l}\text { Food additives: enzymes } \\
\text { like microbial } \\
\text { transglutaminase, protease }\end{array}$ \\
\hline Vitamin D & Sugar, sucrose & \\
\hline Vitamin C & Energy intake & \\
\hline \multicolumn{3}{|l|}{ Vitamin A, E } \\
\hline $\begin{array}{l}\text { B Vitamins: B12, thiamin, } \\
\text { riboflavin, niacin }\end{array}$ & Fat, saturated fatty acids & \\
\hline Folate & High Omega 6 fatty acids & \\
\hline $\begin{array}{l}\text { Zinc, Magnesium, } \\
\text { Selenium }\end{array}$ & $\begin{array}{l}\text { Higher arachidonic acid: } \\
\text { docosahexaenoic acid } \\
\text { ratio }\end{array}$ & \\
\hline $\begin{array}{l}\text { Fibers: oligo fructose, } \\
\text { inulin, fructans }\end{array}$ & $\begin{array}{l}\text { Higher pro-inflammatory } \\
\text { fatty acid profile }\end{array}$ & \\
\hline \multicolumn{3}{|l|}{ Low HDL, Apo A1 } \\
\hline \multicolumn{3}{|l|}{$\begin{array}{l}\text { Lower essential amino } \\
\text { acids }\end{array}$} \\
\hline $\begin{array}{l}\text { Low arachidonic acid: } \\
\text { dihomo- } \gamma \text {-linolenic acid } \\
\text { ratio }\end{array}$ & & \\
\hline
\end{tabular}

Adapted from Taetzsch et al. (4), Melini and Melini (6), Lerner et al. (13), Lerner and Matthias (30), Dennis et al. (46), Penagini et al. (47), Shepherd and Gibson (48), Theethira and Dennis (49), Hosseini et al. (50), Freeman (51), Lerner and Matthias (52), Matthias et al. (53), Matthias and Lerner (54), Lerner and Matthias (55), Allen and Orfila (56), Riezzo et al. (57), Lamacchia et al. (58), and van Hees et al. (59).

of heavy metals like lead, cadmium, mercury, and arsenic [(51), Table 1]. In a recent study, persons following GFD, including non-celiac patients, had increased urinary levels of arsenic and blood levels of mercury, lead, and cadmium compared to persons consuming gluten (66). Since most of the GFD consumers today are non-celiac people, those results relay the accumulation of the toxic heavy metals to the gluten restrictive diet, rather than to CD (67). An additional reason to avoid the gluten-free "fashionistic" fad.

The second potential source of toxic harmful compounds is the enzymes used as food additives in the processed food gluten free products [(50), Table 1]. Microbial transglutaminase (mTg) imitates functionally the autoantigen of $\mathrm{CD}$, namely, the tissue transglutaminase (52). It is a very common additive for cross linking proteins, thus, changing the physical properties, $3 \mathrm{D}$ structure, and immunogenicity by exposing new epitopes, and food quality of many GF products, including in the bakeries (50, 52, 53). Most recently, the enzyme was suggested as an environmental factor that drive CD development (52-55). Its potential deleterious effects in GFD, deserve further exploration.

\section{INCREASED MORBIDITY AND MORTALITY}

Undiagnosed or untreated CD patients are at risk for acute (68) or chronic morbid manifestations and associated diseases.
TABLE 2 | Summary of the causes of increased morbidity on GFD.

\begin{tabular}{lc}
\hline Increased morbidity & References \\
\hline Social leisure activities & $(32,50)$ \\
Metabolic syndrome & $(64)$ \\
Hepatic steatosis & $(64)$ \\
Cardiovascular risks & $(4,62,63)$ \\
Depression & $(56)$ \\
Diabetes 2 & $(4)$ \\
Osteopenia/ osteoporosis & $(69)$ \\
Reduced beneficial microbiota & $(42,70)$ \\
Loss of around 80\% of prebiotics & $(42)$ \\
Obesity & $(4,71)$ \\
\hline
\end{tabular}

However, when compliant to GFD the risk for morbidity and early mortality continues. The background might be inherent to GFD content or to their continued intestinal inflammation. Table 2 summarizes the morbid conditions that CD population on gluten restricted diet might risk.

The increased mortality in CD populations was previously reported. In the largest survey of mortality in $\mathrm{CD}$, mortality was increased in $\mathrm{CD}$, in latent $\mathrm{CD}$ and in patients with intestinal inflammation, hazard ratio (HR) 1.39, 1.35, and 1.72, respectively (20).

The HRs for mortality were highest in the first year of follow-up after diagnosis with total villous atrophy $\mathrm{CD}$ associated with a 2.80-fold increased risk of death, latent (positive serology, negative histology) celiac disease with a 1.81-fold, and inflammation (increased intraepithelial lymphocytes) with a 4.66-fold increase. These startling statistics should bring pause to every Clinician. The only difference post diagnosis for the vast majority of newly diagnosed celiacs is implementation of the GFD. With maintaining inflammation in the intestines on a GFD, the HR for mortality in the first year post-diagnosis was almost double that of total villous atrophy $\mathrm{CD}$. The necessity of comprehensive education for transitioning the patient to a healthy GFD, free from emphasis on GF commercial foods high in calories and low in nutrients, cannot be overemphasized. The most common cause of death in the first year post diagnosis was cardiovascular diseases, followed by malignancy. Excess mortality was independent of the intestinal damage and was observed even on GFD, most probably due to the persistent mucosal inflammation. In fact, after an average of 12 years on a GFD, 31\% of patients still have increased enteric inflammation (72). Suicide rate is increased in CD, latent CD and persistent intestinal inflammation with $\mathrm{HR}$ of $1.55,1.06,1.96$, respectively, compared to the general population, when done on a Swedish cohort (73). Interestingly but alarming, CD diagnosed in childhood was associated with a $40 \%$ increase in suicide risk. It should be noticed that naïve and treated CD is frequently comorbid with multiple additional autoimmune diseases like autoimmune thyroiditis, type 1 diabetes, IBD and many more $(14,26,27,74)$. Cancers like non-Hodgkin lymphoma and other gastrointestinal malignancies and genetic conditions like Downs, Turner, and Williams syndromes are also associated with CD, 
thus adding to the morbidity and mortality, including when on gluten withdrawal. At the end of the day, it is possible that persistent inflammation increased both overall mortality rate and suicide risk, despite following GFD.

\section{GFD AND MENTAL HEALTH}

Evidence points to the nervous system as the prime site of gluten damage. Literature reported that gluten can cause neurological harm through a combination of cross reacting antibodies, immune complex disease, and direct toxicity (75). The association between CD and other gluten related conditions with behavioral and psychiatric disorders was extensively reported and summarized recently (76-78). The spectrum includes anxiety, dysthymia, depression, attention-deficit hyperactive disorders, mood and sleep disorders, mal social adaptation, substance-related, addictive and neurocognitive disorders, suicide attempts, learning disabilities, feeding and eating disorders, bipolar syndromes, schizophrenia, and autistic spectrum disorders. Those disorders appeared across different age groups, in both genders and some are considered as extra-intestinal manifestation of CD. The strongest association was reported with depression $(59,76)$, but, the association between chronic medical conditions and depression is wellestablished. It might be bidirectional since physical illness or disability often worsen the mental disorder and vice versa (79). More so, dietary modification, including GFD in gluten related conditions, may be associated with pathological eating practices (80). Compliance with GFD is a tough alley (28), associated with major changes in daily lifestyle routine and activities and eating habits, many times stressful and difficult to accept $(81,82)$. The underlying mechanisms that induce those psycho-social-behavioral disorders, while on GFD, are not understood. Nutritional and vitamin deficiencies (59), an immune dysregulation, cerebral hypo perfusion (83), the gut "feeling of the brain" in the gut-brain axis (84) or the stress of adherence to GFD, have been suggested (76).

\section{GFD SIDE EFFECTS: CLOSING THE GAPS}

Taking into account the tough alley and the contemporary torrid times in complying with a strict GFD (28), sincere and practical efforts should be implemented to close the gaps. Following are some suggestions to avoid the detrimental effect of GF product consumption toward a more personalized nutrition, tailored to the individual needs.

Gluten restriction should be accompanied by healthier food to avoid nutritional deficiencies, toxicity of alternative non-gluten containing prolamins, morbidity and finally early mortality. In this regards, it is advised to adapt the Mediterranean diet, the most studied and successful one against major noncommunicable chronic diseases (85). It is rich in fibers, antioxidants, anti-inflammatory mediators, vitamins, trace elements, minerals, beneficial fatty acids, qualified proteins, bone building compounds, metabolically balanced and affects the enteric microbiome favorably $(86,87)$. Enriched cow's milk and dairy products are salutogenic to $\mathrm{CD}$ patients and their lactose intolerance is transitory while on gluten restriction $(88,89)$. If a patient has neither clinical nor serology evidence of a sensitivity to cow's milk (90), and they are not homozygous for a primary lactase deficiency (91), the nutrient dense platform of milk may be of substantial value in supplying macro and micro nutrients for rebuilding an inflammatory-damaged terrain.

Asking a patient to abstain from a most-common food in their diet, often eaten in some form multiple times per day, is an extremely challenging directive fraught with noncompliance absent expert on-going advice. Early and effective consultation with a gluten knowledgeable, food labeling skilled, Dietitian, Nutritionist or Health Coach (28), increasing the intake of pseudo-cereals, polyphenol-rich fruits and vegetables, encouraging natural GF foods, focused efforts on rebuilding a balanced non-inflammatory microbiome, increasing the patient's education on the disease evolvement, GF products and follow ups, in order to improve adherence and establish a healthy balanced diet $(6,47,49,50,92)$ is of essential nature in reducing the increased risk of morbidity and mortality. Very important is the physician-dietitian-patient trustful relationship and the team communication for the patient's successful recovery and adherence to the dietary restriction. Not less important is the periodic laboratory test to check for CD associated serological markers and to detect any nutritional deficiencies.

\section{CONCLUSIONS}

GFD is the only proved therapy for CD and is crucial in the other gluten related conditions. It reduces activating an inflammatory cascade in the intestines, rehabilitates the intestine, normalizes the associated biomarkers and can treat or improve some of the extra-intestinal manifestations. However, despite being an effective therapy, GF products suffer from limitations, side effects and might bear risks if not detected and dealt appropriately. Nutritional deficiencies, toxic components, unbalanced diet, increased morbidity, mortality and psychiatric or behavioral abnormality, are a few examples. The treating team should be aware of the potential dark side of gluten restriction, diagnose those abnormalities and offer adequate solutions to improve the patient's health and quality of life.

\section{AUTHOR CONTRIBUTIONS}

$\mathrm{AL}$ and TO'B: conceptualization. TO'B: methodology. AL: formal analysis. TM: resources. AL and TO'B: data curation. AL: writing-original draft preparation. AL, TO'B, and TM: writing-review and editing. All authors read and approved the final manuscript.

\section{ACKNOWLEDGMENTS}

The authors thank Dr. Ramesh Ajay for editing and revising the manuscript. 


\section{REFERENCES}

1. Hedden P. The genes of the Green Revolution. Trends Genet. (2003) 19:5-9. doi: 10.1016/S0168-9525(02)00009-4

2. Fasano A, Catassi C. Current approaches to diagnosis and treatment of celiac disease: an evolving spectrum. Gastroenterology. (2001) 120:636-51. doi: 10.1053/gast.2001.22123

3. Umberto Volta U, Bardella MT, Calabrò A, Troncone R, Corazza GR, and The Study Group for Non-Celiac Gluten Sensitivity. An Italian prospective multicenter survey on patients suspected of having non-celiac gluten sensitivity. BMC Med. (2014) 12:85. doi: 10.1186/1741-7015-12-85

4. Taetzsch A, Das SK, Brown C, Krauss A, Silver RE, Roberts SB. Are gluten-free diets more nutritious? An evaluation of self-selected and recommended gluten-free and gluten-containing dietary patterns. Nutrients. (2018) 10:E1881. doi: 10.3390/nu10121881

5. Shewry PR, Tatham AS, Improving wheat to remove coeliac epitopes but retain functionality. J Cereal Sci. (2016) 67:12-21. doi: 10.1016/j.jcs.2015.06.005

6. Melini V, Melini F. Gluten-free diet: gaps and needs for a healthier diet. Nutrients. (2019) 11:E170. doi: 10.3390/nu11010170

7. Bach JF. The effect of infections on susceptibility to autoimmune and allergic diseases. N Engl J Med. (2002) 347:911-20. doi: 10.1056/NEJMra020100

8. Lerner A, Jeremias P, Matthias T. The world incidence and prevalence of autoimmune diseases is increasing: a review. Int J Celiac Dis. (2015) 3:151-5. doi: 10.12691/ijcd-3-4-8

9. Béjot Y, Daubail B, Jacquin A, Durier J, Osseby GV, Rouaud O, et al. Trends in the incidence of ischaemic stroke in young adults between 1985 and 2011: the Dijon Stroke Registry. J Neurol Neurosurg Psychiatry. (2014) 85:509-13. doi: 10.1136/jnnp-2013-306203

10. Scudellari M. News feature: cleaning up the hygiene hypothesis. Proc Natl Acad Sci USA. (2017) 114:1433-6. doi: 10.1073/pnas.1700688114

11. Vandegrift R, Bateman AC, Siemens KN, Nguyen M, Wilson HE3, Green $\mathrm{JL}$, et al. Cleanliness in context: reconciling hygiene with a modern microbial perspective. Microbiome. (2017) 5:76. doi: 10.1186/s40168-0170294-2

12. Lerner A, Aminov R, Matthias T. Dysbiosis may trigger autoimmune diseases via inappropriate posttranslational modification of host proteins. Front Microbiol. (2016) 7:84. doi: 10.3389/fmicb.2016.00084

13. Lerner A, Aminov R, Matthias T. Intestinal dysbiotic transglutaminases are potential environmental drivers of systemic autoimmunogenesis. Front Microbiol. (2017) 8:66. doi: 10.3389/fmicb.2017.00066

14. Lerner A, Matthias T. GUT-the Trojan horse in remote organs' autoimmunity. J Clin Cell Immunol. (2016) 7:401. doi: 10.4172/2155-9899.1000401

15. Elli L, Branchi F, Tomba C, Villalta D, Norsa L, Ferretti F, et al. Diagnosis of gluten related disorders: celiac disease, wheat allergy and non-celiac gluten sensitivity. World J Gastroenterol. (2015) 21:7110-9. doi: 10.3748/wjg.v21.i23.7110

16. Sapone A, Bai JC, Ciacci C, Dolinsek J, Green PH, Hadjivassiliou M, et al. Spectrum of gluten-related disorders: consensus on new nomenclature and classification. BMC Med. (2012) 10:13. doi: 10.1186/1741-7015-10-13

17. Lerner A. The enigma of oats in nutritional therapy for celiac disease. Int $J$ Celiac Dis. (2014) 2:110-4. doi: 10.12691/ijcd-2-3-1

18. Lerner A, Jeremias P, Matthias T. The world incidence of celiac disease is increasing: a review. Int J Recent Sci Res. (2015) 6:5491-6.

19. Lanzini A, Lanzarotto F, Villanacci V, Mora A, Bertolazzi S, Turini D, et al. Complete recovery of intestinal mucosa occurs very rarely in adult coeliac patients despite adherence to gluten-free diet. Aliment Pharmacol Ther. (2009) 29:1299-308. doi: 10.1111/j.1365-2036.2009.03992.x

20. Ludvigsson JF, Montgomery SM, Ekbom A, Brandt L, Granath F. Smallintestinal histopathology and mortality risk in celiac disease. JAMA. (2009) 302:1171-8. doi: 10.1001/jama.2009.1320

21. Zanini B, Marullo M, Villanacci V, Salemme M, Lanzarotto F, Ricci C, et al. Persistent intraepithelial lymphocytosis in celiac patients adhering to glutenfree diet is not abolished despite a gluten contamination elimination diet. Nutrients. (2016) 8:525. doi: 10.3390/nu8090525

22. All Standards|CODEXALIMENTARIUS FAO-WHO. Available online at: http://www.fao.org/fao-who-codexalimentarius/codex-texts/list-standards/ jp/ (accessed December 12, 2018).
23. Ierardi E, Losurdo G, Piscitelli D, Giorgio F, Amoruso A, Iannone A, et al. Biological markers for non-celiac gluten sensitivity: a question awaiting for a convincing answer. Gastroenterol Hepatol Bed Bench. (2018) 11:203-8.

24. Volta U, De Giorgio R, Caio G, Uhde M, Manfredini R, Alaedini A. Nonceliac wheat sensitivity: an immune-mediated condition with systemic manifestations. Gastroenterol Clin North Am. (2019) 48:165-82. doi: 10.1016/j.gtc.2018.09.012

25. Khalid AN, McMains KC. Gluten sensitivity: fact or fashion statement? Curr Opin Otolaryngol Head Neck Surg. (2016) 24:238-40. doi: 10.1097/MOO.0000000000000263

26. Lerner A, Matthias T. Extraintestinal manifestations of CD: Common pathways in the gut-remote organs' axes. Int J Celiac Dis. (2017) 5:24-7. doi: 10.12691/ijcd-5-1-5

27. Lerner A, Matthias T, Wusterhausen P. Autoimmunity in celiac disease: extra-intestinal manifestations. Autoimm Rev. (2019) 18:241-6. doi: 10.1016/j.autrev.2018.09.010

28. Lerner A, Matthias T. Gluten free diet- tough alley in torrid time. Int J Celiac Dis. (2017) 5:50-5. doi: 10.12691/ijcd-5-2-4

29. Samasca G, Lerner A, Sur G, Lupan L, Makovicky P, Matthias T, et al. Challenging in gluten-free diet in celiac disease: Prague consensus. Eur J Clin Invest. (2017) 47:394-7. doi: 10.1111/eci.12755

30. Lerner A, Matthias T. Changes in intestinal tight junction permeability associated with industrial food additives explain the rising incidence of autoimmune disease. Autoimmun Rev. (2015) 14:479-89. doi: 10.1016/j.autrev.2015.01.009

31. Newberry C, McKnight L, Sarav M, Pickett-Blakely O. Going gluten free: the history and nutritional implications of today's most popular diet. Curr Gastroenterol Rep. (2017) 19:54. doi: 10.1007/s11894-017-0597-2

32. Pearlman M, Casey L. Who should be gluten-free? A review for the general practitioner. Med Clin North Am. (2019) 103:89-99. doi: 10.1016/j.mcna.2018.08.011

33. Silvester JA, Weiten D, Graff LA, Walker JR, Duerksen DR. Is it gluten-free? Relationship between self-reported gluten-free diet adherence and knowledge of gluten content of foods. Nutrition. (2016) 32:777-83. doi: 10.1016/j.nut.2016.01.021

34. Paganizza S, Zanotti R, D’Odorico A, Scapolo P, Canova C. Is adherence to a gluten-free diet by adult patients with celiac disease influenced by their knowledge of the gluten content of foods? Gastroenterol Nurs. (2019) 42:55-64. doi: 10.1097/SGA.0000000000000368

35. Freeman HJ. Dietary compliance in celiac disease. World J Gastroenterol. (2017) 23:2635-9. doi: 10.3748/wjg.v23.i15.2635

36. Cohen IS, Day AS, Shaoul R. Gluten in celiac disease-more or less? Rambam Maimonides Med J. (2019) 10:e0007. doi: 10.5041/RMMJ.10360

37. Buchman AL. Celiac disease, gluten-free, and today's fashionista. Gastroenterol Clin North Am. (2019) 48:xiii-xiv. doi: 10.1016/j.gtc.2018.10.002

38. David L, Maurice C, Carmody R, Gootenberg D, Button J, Wolfe B, et al. Diet rapidly and reproducibly alters the human gut microbiome. Nature. (2014) 505:559-63. doi: 10.1038/nature 12820

39. Di Cagno R, De Angelis M, De Pasquale I, Ndagijimana M, Vernocchi P, Ricciuti $\mathrm{P}$, et al. Duodenal and faecal microbiota of celiac children: molecular, phenotype and metabolome characterization. BMC Microbiol. (2011) 11:219. doi: 10.1186/1471-2180-11-219

40. Sanz Y. Effects of a gluten-free diet on gut microbiota and immune function in healthy adult humans. Gut Microbes. (2010) 1:135-7. doi: 10.4161/gmic.1.3.11868

41. Moshfegh AJ, Friday JE, Goldman JP, Ahuja JK. Presence of inulin and oligofructose in the diets of Americans. J Nutr. (1999) 129:1407S-1S. doi: $10.1093 / \mathrm{jn} / 129.7 .1407 \mathrm{~S}$

42. Jackson FW, Effects of a gluten-free diet on gut microbiota and immune function in healthy adult human subjects - comment by Jackson. Br J Nutr. (2010) 104:773. doi: 10.1017/S0007114510001960

43. Ascher S, Reinhardt C. The gut microbiota: an emerging risk factor for cardiovascular and cerebrovascular disease. Eur J Immunol. (2018) 48:564-75. doi: 10.1002/eji.201646879

44. Wang Z, Klipfell E, Bennett BJ, Koeth R, Levison BS, Dugar B, et al. Gut flora metabolism of phosphatidylcholine promotes cardiovascular disease. Nature. (2011) 472:57-63. doi: 10.1038/nature09922 
45. Zhu W, Gregory JC, Org E, Buffa JA, Gupta N, Wang Z, et al. Gut microbial metabolite TMAO enhances platelet hyperreactivity and thrombosis risk. Cell. (2016) 165:111-24. doi: 10.1016/j.cell.2016.02.011

46. Dennis M, Lee AR, McCarthy T. Nutritional considerations of the gluten-free diet. Gastroenterol Clin North Am. (2019) 48:53-72. doi: 10.1016/j.gtc.2018.09.002

47. Penagini F, Dilillo D, Meneghin F, Mameli C, Fabiano V, Zuccotti GV. Glutenfree diet in children: an approach to a nutritionally adequate and balanced diet. Nutrients. (2013) 5:4553-65. doi: 10.3390/nu5114553

48. Shepherd SJ, Gibson PR. Nutritional inadequacies of the gluten-free diet in both recently-diagnosed and long-term patients with coeliac disease. J Hum Nutr Diet. (2013) 26:349-58. doi: 10.1111/jhn.12018

49. Theethira TG, Dennis M. Celiac disease and the gluten-free diet: consequences and recommendations for improvement. Dig Dis. (2015) 33:175-82. doi: $10.1159 / 000369504$

50. Hosseini SM, Soltanizadeh N, Mirmoghtadaee P, Banavand P, Mirmoghtadaie L, Shojaee-Aliabadi S. Gluten-free products in celiac disease: nutritional and technological challenges and solutions. J Res Med Sci. (2018) 23:109. doi: 10.4103/jrms.JRMS_666_18

51. Freeman HJ. Adverse effects of gluten-free diets. Int J Celiac Dis. (2018) 6:71-3. doi: 10.12691/ijcd-6-3-7

52. Lerner A, Matthias T. Possible association between celiac disease and bacterial transglutaminase in food processing: a hypothesis. Nutr Rev. (2015) 73:54452. doi: 10.1093/nutrit/nuv011

53. Matthias T, Jeremias $\mathrm{P}$, Neidhöfer S, Lerner A. The industrial food additive microbial transglutaminase, mimics the tissue transglutaminase and is immunogenic in celiac disease patients. Autoimm Rev. (2016) 15:1111-9. doi: 10.1016/j.autrev.2016.09.011

54. Matthias T, Lerner A. Microbial transglutaminase is immunogenic and potentially pathogenic in pediatric celiac disease. Front. Pediatr. (2018) 6:389. doi: 10.3389/fped.2018.00389

55. Lerner A, Matthias T. Microbial transglutaminase is beneficial to food industries but a caveat to public health. Med One. (2019) 4:e190001. doi: 10.20900/mo.20190001

56. Allen B, Orfila C. The availability and nutritional adequacy of glutenfree bread and pasta. Nutrients. (2018) 10:E1370. doi: 10.3390/nu101 01370

57. Riezzo G, Ferreri C, Orlando A, Martulli M, D’Attoma B, Russo F. Lipidomic analysis of fatty acids in erythrocytes of coeliac patients before and after a gluten-free diet intervention: a comparison with healthy subjects. Br J Nutr. (2014) 112:1787-96. doi: 10.1017/S0007114514002815

58. Lamacchia C, Camarca A, Picascia S, Di Luccia A, Gianfrani C. Cereal-based gluten-free food: how to reconcile nutritional and technological properties of wheat proteins with safety for celiac disease patients. Nutrients. (2014) 6:575-90. doi: 10.3390/nu6020575

59. van Hees NJ, Giltay EJ, Tielemans SM, Geleijnse JM, Puvill T, Janssen N, et al. Essential amino acids in the gluten-free diet and serum in relation to depression in patients with celiac disease. PLOS ONE. (2015) 10:e0122619. doi: 10.1371/journal.pone.0122619

60. Hager A-S, Wolter A, Jacob F, Zannini E, Arendt EK. Nutritional properties and ultra-structure of commercial gluten free flours from different botanical sources compared to wheat flours. J Cereal Sci. (2012) 56:239-47. doi: 10.1016/j.jcs.2012.06.005

61. Lerner A, Matthias T. Editorial: Celiac disease: intestinal, heart and skin inter-connections. Int J Celiac Dis. (2015) 3:28-30. doi: 10.12691/ijcd-3-1-6

62. Anania C, Pacifico L, Olivero F, Perla FM, Chiesa C. Cardiometabolic risk factors in children with celiac disease on a gluten-free diet. World J Clin Pediatr. (2017) 6:143-8. doi: 10.5409/wjcp.v6.i3.143

63. Siriwardhane T, Krishna K, Devarajan K, Ranganathan V, Jayaraman V, Wang $\mathrm{T}$, et al. Insights into cardiovascular risk and nutritional status in subjects with wheat-related disorders. Biomarkers. (2019) 24:303-7. doi: 10.1080/1354750X.2019.1578829

64. Ciccone A, Gabrieli D, Cardinale R, Di Ruscio M, Vernia F, Stefanelli G, et al. Metabolic alterations in celiac disease occurring after following a gluten-free diet. Digestion. (2018). doi: 10.1159/000495749. [Epub ahead of print].

65. Ortiz-Sánchez JP, Cabrera-Chávez F, de la Barca AM Maize prolamins could induce a gluten-like cellular immune response in some celiac disease patients. Nutrients. (2013) 5:4174-83. doi: 10.3390/nu5104174
66. Raehsler SL, Choung RS, Marietta EV, Murray JA. Accumulation of heavy metals in people on a gluten-free diet. Clin Gastroenterol Hepatol. (2018) 16:244-51. doi: 10.1016/j.cgh.2017.01.034

67. Patel NK, Lacy BE. Another reason to avoid the gluten-free fad? Clin Gastroenterol Hepatol. (2018) 16:184-5. doi: 10.1016/j.cgh.2017.10.002

68. Lerner A, Matthias T. A silent or hypo-symptomatic disease can erupt: acute presentations of celiac disease. Int J Celiac Dis. (2017) 5:129-32. doi: 10.12691/ijcd-5-4-1

69. Kotze LM, Skare T, Vinholi A, Jurkonis L, Nisihara R. Impact of a gluten-free diet on bone mineral density in celiac patients. Rev Esp Enferm Dig. (2016) 108:84-8. doi: 10.17235/reed.2015.3953/2015

70. De Palma G, Nadal I, Collado MC, Sanz Y. Effects of a gluten-free diet on gut microbiota and immune function in healthy adult human subjects. Br J Nutr. (2009) 102:1154-60. doi: 10.1017/S0007114509371767

71. Eliyah Livshits O, Shauol R, Reifen R, Matthias T, Lerner A. Can celiac disease present along with childhood obesity? Int J Celiac Dis. (2017) 5:19-23. doi: 10.12691/ijcd-5-1-7

72. Kristjánsson G, Högman $M$, Venge $P$, Hällgren R. Gut mucosal granulocyte activation precedes nitric oxide production: studies in coeliac patients challenged with gluten and corn. Gut. (2005) 54:769-74. doi: 10.1136/gut.2004.057174

73. Ludvigsson JF, Sellgren C, Runeson B, Långström N, Lichtenstein P. Increased suicide risk in coeliac disease-a Swedish nationwide cohort study. Dig Liver Dis. (2011) 43:616-22. doi: 10.1016/j.dld.2011.02.009

74. Samasca G, Ramesh A, Sur D, Cornel A, Sur L, Flocaa E, et al. Polyautoimmunity - The missing ingredient. Autoimm Rev. (2018) 17:840-1. doi: 10.1016/j.autrev.2018.03.008

75. Abenavoli L. Nervous system in the gluten syndrome: a close relationship. Med Hypotheses. (2010) 74:204-5. doi: 10.1016/j.mehy.2009.08.012

76. Slim M, Rico-Villademoros F, Calandre EP. Psychiatric comorbidity in children and adults with gluten-related disorders: a narrative review. Nutrients. (2018) 10:E875. doi: 10.3390/nu100 70875

77. Brietzke E, Cerqueira RO, Mansur RB, McIntyre RS. Gluten related illnesses and severe mental disorders: a comprehensive review. Neurosci Biobehav Rev. (2018) 84:368-75. doi: 10.1016/j.neubiorev.2017. 08.009

78. Cossu G, Carta MG, Contu F, Mela Q, Demelia L, Elli L, et al. Coeliac disease and psychiatric comorbidity: epidemiology, pathophysiological mechanisms, quality-of-life, and gluten-free diet effects. Int Rev Psychiatry. (2017) 29:489-503. doi: 10.1080/09540261.2017.13 14952

79. Katon WJ. Epidemiology and treatment of depression in patients with chronic medical illness. Dialogues Clin Neurosci. (2011) 13:7-23.

80. Wagner G, Zeiler M, Berger G, Huber WD, Favaro A, Santonastaso P, et al. Eating disorders in adolescents with celiac disease: influence of personality characteristics and coping. Eur Eat Disord Rev. (2015) 23:361-70. doi: 10.1002/erv.2376

81. Mazzone L, Reale L, Spina M, Guarnera M, Lionetti E, Martorana $\mathrm{S}$, et al. Compliant gluten-free children with celiac disease: an evaluation of psychological distress. BMC Pediatr. (2011) 11:46. doi: 10.1186/1471-2431-11-46

82. Leffler DA, Edwards-George J, Dennis M, Schuppan D, Cook F, Franko DL, et al. Factors that influence adherence to a gluten-free diet in adults with celiac disease. Dig Dis Sci. (2008) 53:1573-81. doi: 10.1007/s10620-0070055-3

83. Abenavoli L, Leggio L, Di Giuda D, Gasbarrini G, Addolorato G. Neurologic disorders in patients with celiac disease: are they mediated by brain perfusion changes? Pediatrics. (2004) 114:1734. doi: 10.1542/peds.2004-1248

84. Lerner A, Neidhöfer S, Matthias T. The gut microbiome feelings of the brain: perspective for Non-Microbiologists. Microorganisms. (2017) 5:66. doi: 10.3390/microorganisms5040066

85. Morreale F, Agnoli C, Roncoroni L, Sieri S, Lombardo V, Mazzeo T, et al. Are the dietary habits of treated individuals with celiac disease adherent to a Mediterranean diet? Nutr Metab Cardiovasc Dis. (2018) 28:1148-54. doi: 10.1016/j.numecd.2018.06.021

86. Dernini S, Berry EM. Mediterranean diet: from a healthy diet to a sustainable dietary pattern. Front Nutr. (2015) 2:15. doi: 10.3389/fnut.2015.00015 
87. Garcia-Mantrana I, Selma-Royo M, Alcantara C, Collado MC. Shifts on gut microbiota associated to mediterranean diet adherence and specific dietary intakes on general adult population. Front Microbiol. (2018) 9:890. doi: $10.3389 /$ fmicb.2018.00890

88. Lerner A, Matthias T. The salutogenic effects of cow's milk and dairy products in celiac disease. J Clin Cell. Immunol. (2018) 9:549-54. doi: 10.4172/2155-9899.1000549t

89. Lerner A, Wusterhausen P, Ramesh A, Matthias T. Celiac disease and lactose intolerance. Int J Celiac Dis. (2018) 6:68-70. doi: 10.12691/ijcd-6-3-8

90. Lambbert J, Vojdani A. Correlation of tissue antibodies and food immune reactivity in randomly selected patient specimens. J Clin Cell Immunol. (2017) 8:521. doi: 10.4172/2155-9899.1000521

91. Basso MS, Luciano R, Ferretti F, Muraca M, Panetta F, Bracci F, et al. Association between celiac disease and primary lactase deficiency. Eur J Clin Nutr. (2012) 66:1364-5. doi: 10.1038/ejen.2012.153
92. Bascuñán KA, Vespa MC, Araya M. Celiac disease: understanding the gluten-free diet. Eur J Nutr. (2017) 56:449-59. doi: 10.1007/s00394-016$1238-5$

Conflict of Interest: The authors declare that the research was conducted in the absence of any commercial or financial relationships that could be construed as a potential conflict of interest.

Copyright $\odot 2019$ Lerner, O'Bryan and Matthias. This is an open-access article distributed under the terms of the Creative Commons Attribution License (CC BY). The use, distribution or reproduction in other forums is permitted, provided the original author(s) and the copyright owner(s) are credited and that the original publication in this journal is cited, in accordance with accepted academic practice. No use, distribution or reproduction is permitted which does not comply with these terms. 